\title{
El periurbano de Mar del Plata (Argentina): clasificación digital de los usos del suelo y análisis de las transformaciones en el cinturón hortícola
}

\author{
The peri-urban Mar del Plata (Argentina): digital classification of \\ land uses and analysis of transformations in the horticultural belt
}

\author{
Daiana Yael Daga ${ }^{1}$ \\ CONICET-Universidad Nacional del Centro de la Provincia \\ de Buenos Aires Argentina \\ Laura Zulaica ${ }^{2}$ \\ CONICET-Universidad Nacional de Mar del Plata, Argentina \\ Patricia Vazquez ${ }^{3}$ \\ CONICET-Universidad Nacional del Centro de la Provincia \\ de Buenos Aires, Argentina
}

\begin{abstract}
Resumen
La sustentabilidad de las ciudades constituye uno de los propósitos más relevantes de los últimos tiempos. En ese contexto, las áreas periurbanas adquieren un rol prioritario ya que conjugan problemáticas sociales y ecológicas asociadas con las actividades que allí se desarrollan. En este marco, el objetivo del presente trabajo es identificar los usos del suelo presentes en el periurbano de Mar del

1 Doctoranda del programa de Ciencias Agrarias de la Universidad Nacional de Rosario (Santa Fe, Argentina). Lic. en Diagnóstico y Gestión Ambiental. Becaria doctoral del Consejo Nacional de Investigaciones Científicas y Técnicas. Centaro de Estudios Sociales de América Latina, Facultad de Ciencias Humanas, CONICETUniversidad Nacional del Centro de la Provincia de Buenos Aires. Paraje Arroyo Seco s/n, Tandil, Buenos Aires, Argentina. Correo electrónico: daianadaga@conicet.gov.ar. http://orcid.org/0000-0001-7578-8478

2 Doctora en Geografía. Investigadora Adjunta del Consejo Nacional de Investigaciones Científicas y Técnicas. Instituto del Hábitat y del Ambiente, Facultad de Arquitectura, Urbanismo y Diseño, Universidad Nacional de Mar del Plata. Funes 3350, Mar del Plata, Buenos Aires, Argentina. Correo electrónico: laurazulaica@conicet.gov.ar. https://orcid.org/0000-0001-8101-5957

3 Doctora en Ciencias Agrarias. Investigadora Adjunta del Consejo Nacional de Investigaciones Científicas y Técnicas. Centro de Estudios Sociales de América Latina, Facultad de Ciencias Humanas, Universidad Nacional del Centro de la Provincia de Buenos Aires. Paraje Arroyo Seco s/n, Tandil, Buenos Aires, Argentina. Correo electrónico: patriciavazquez@conicet.gov.ar. https://orcid.org/0000-0002-4209-4901
\end{abstract}


Daiana Yael Daga - Laura Zulaica - Patricia Vazquez The peri-urban Mar del Plata (Argentina): digital classification of land uses and analysis of transformations in the horticultural belt

Plata hacia el año 2018 y caracterizar la evolución de la actividad hortícola desde sus inicios hasta la actualidad. En el Partido se clasificaron sobre imágenes satelitales 6 usos principales, entre los cuales las "áreas hortícolas" abarcan apenas un 7\%, pero contribuyen significativamente a la economía local. A partir del análisis de la expansión e intensificación de estas áreas, se espera profundizar en los impactos generados por la actividad hortícola, a fin de alcanzar una mayor sustentabilidad en el territorio local.

Palabras clave: clasificaciones satelitales, sistemas de información geográfica, horticultura, interfase urbano- rural.

\begin{abstract}
The sustainability of cities is one of the most relevant purposes of recent times. In this context, peri-urban areas acquire a priority role as they combine social and ecological problems associated with the activities that are developed there. Within this framework, the objective of the present work is to identify the land uses present in the peri-urban area of Mar del Plata (Argentina) in the year 2018 and characterize the evolution of the horticultural activity from its beginnings to the present. In the County, 6 main uses, were classified on satellite images, among which "horticultural areas" cover only $7 \%$ but contribute significantly to the local economy. From the analysis of the expansion and intensification of these areas it is expected to deepen the discussion regarding the impacts generated by the horticultural activity with the finality of achieving greater sustainability in the local territory.
\end{abstract}

Keywords: satellite classifications, geographic information systems, horticulture, urban- rural interface.

\title{
Introducción
}

La gestión de las ciudades hacia objetivos de sustentabilidad constituye uno de los desafíos más apremiantes de nuestros tiempos. Lograr que los asentamientos humanos sean seguros, inclusivos y resilientes es uno de los Objetivos de Desarrollo Sostenible promovidos por los Estados Miembros de la Organización de las Naciones Unidas (ONU) en la Agenda fijada hacia 2030. En este contexto, las áreas periurbanas adquieren un papel prioritario ya que conjugan numerosas problemáticas y conflictos ambientales asociados con la heterogeneidad de actividades que se desarrollan en estos espacios, involucrando una multiplicidad de actores.

Considerando los usos del suelo, el periurbano puede definirse como un sistema en mosaico donde coexisten agroecosistemas, ecosistemas consumidores o aglomeraciones urbanas y ecosistemas naturales remanentes cada vez más reducidos (Di Pace, 2001). Además, se caracteriza por ser un territorio frágil, en mutación y transición, de difícil permanencia en el tiempo y susceptible a nuevas intervenciones (Barsky et al., 2010). 
Una de las particularidades de las áreas periurbanas es su contribución a la producción y abastecimiento de alimentos frutihortícolas a las ciudades sobre las que se asientan y también a la región, a través de mercados concentradores y de distribución.

En función de lo mencionado, una de las manifestaciones paisajísticas y sociales más características de estas áreas es el entramado de explotaciones primario-intensivas que conforman los denominados cinturones verdes. Estos cinturones se emplazan en cuñas, intersticios, áreas vacantes características de los espacios de interfase urbano-rural. En comparación con otras producciones agrarias extensivas que operan a mayor escala y manejan grandes volúmenes, la ventaja competitiva de las explotaciones primario-intensivas radica en la proximidad a la ciudad (Barsky, 2010). Se trata de quintas o huertas familiares, como así también otras más empresariales, cuya producción se destina especialmente a verduras de hoja y hortalizas de estación y cumplen funciones de abastecimiento alimentario a la población de las ciudades (Di Pace y Bartrons, 2004).

En Argentina, la provincia de Buenos Aires concentra el 19,7\% del total de la superficie hortícola (INDEC, 2002) y alberga una importante variedad de producciones. Se estima que los cinturones hortícolas bonaerenses producen alrededor de 16 tipos de hortalizas (Ministerio de Educación de la Nación, 2010). Desde la última década, los cinturones de las ciudades de La Plata y Mar del Plata, se caracterizan por la intensificación de la producción hortícola respecto de otros cercanos a la ciudad de Buenos Aires, donde la urbanización generó una dinámica de desplazamiento de estas actividades (Barsky, 2005).

De acuerdo con lo anterior, los sistemas hortícolas se encuentran localizados en áreas periurbanas complejas y conflictivas en sus actividades, que se hallan en permanente transformación y redefinición. Por este motivo y considerando el rol preponderante que poseen para las ciudades, resulta relevante la identificación y el análisis de la distribución espacial de estos sistemas a fin de caracterizar el área en la que se asientan y monitorear su evolución a lo largo del tiempo.

En este sentido, las imágenes satelitales constituyen una importante fuente de información para mapear y caracterizar los usos del suelo y la estructura del paisaje tanto a escala regional (Alperín et al., 2002), como así también local. Además, representan una herramienta efectiva para 
identificar las actividades, recursos naturales y monitorear sus transformaciones de una manera relativamente sencilla y a bajo costo (Vazquez y Rivas, 2009).

Desde la perspectiva metodológica, la clasificación digital constituye uno de los procedimientos más utilizados en teledetección para transformar los datos contenidos en las imágenes satelitales en información temática (Argañaraz y Entraigas, 2011), destacándose numerosos estudios en regiones latinoamericanas (Beuchle et al., 2015; Piazza et al., 2016; Jaramillo y Antunes, 2018) y argentinas (Lara y Gandini, 2014; Volante y Paruelo, 2015; Sequeira et al., 2016; Vazquez et al., 2019).

Por otra parte, aquellos datos procedentes de la teledetección pueden ser combinados con otra información geoespacial en el entorno de un Sistema de Información Geográfica (SIG) (Richards y Jia, 2006). De forma general, ambas herramientas poseen la capacidad de simplificar la tarea de recolección de datos para caracterizar las cubiertas terrestres, paisajes, usos del suelo, recursos naturales en general, y examinar su variación en distintos períodos de tiempo. De esta manera, la identificación de los usos del suelo y el análisis de sus cambios, cobra importancia en la gestión ambiental de territorios urbanos, periurbanos y rurales. Asimismo, es posible afirmar que, en el caso de áreas de características complejas y en constante transformación como son las áreas periurbanas, este tipo de análisis y técnicas poseen un papel destacado.

La ciudad de Mar del Plata es la cabecera del partido de General Pueyrredon y se dispone sobre el océano Atlántico con una extensión urbana costera de aproximadamente $50 \mathrm{~km}$. El Partido ocupa 1460,74 km² y se localiza al sudeste de la provincia de Buenos Aires, limitando al noreste con el partido de Mar Chiquita, al sudoeste con General Alvarado, al noroeste con el partido de Balcarce y al sudeste con el océano Atlántico (Figura 1). Si bien en el área conviven diversos usos, se destaca el hortícola, conformando la segunda actividad en términos de valor agregado del sector primario local (Atucha et al., 2012). De esta forma, contribuye significativamente al Producto Bruto Geográfico (PBG) y posiciona a Mar del Plata como el segundo cinturón verde en importancia del país, después de La Plata, abasteciendo tanto al mercado local como regional.

El cinturón comprende una franja de $25 \mathrm{~km}$ de largo que bordea a la ciudad, principalmente en torno a las rutas 226 y 88 ; formando parte de su 
periurbano, el cual abarca el 23,49\% del Partido y fue definido en trabajos previos (Ferraro et al., 2013; Zulaica y Ferraro, 2013). La horticultura se extiende mayoritariamente en áreas próximas a las localidades de Batán y Sierra de los Padres y en otros asentamientos del periurbano entre los que se destacan La Gloria de la Peregrina, Santa Paula y Colinas Verdes. Con el arribo de cambios tecnológicos en los años '90, representados por la aparición del invernáculo, riego por goteo, plantines y materiales genéticos resistentes (Carrozzi y Viteri, 2002), el cinturón hortícola de Mar del Plata se vio inmerso en una etapa de expansión e intensificación. Según datos de INTA (2017), la superficie destinada a la horticultura es de aproximadamente $95 \mathrm{~km}^{2}$ a campo y $6,5 \mathrm{~km}^{2}$ bajo cubierta.

En función de lo señalado, el objetivo del presente trabajo es identificar los usos del suelo presentes en el periurbano de Mar del Plata hacia el año 2018 y caracterizar la evolución de la actividad hortícola desde sus inicios hasta la actualidad. Previo a ello, es necesario definir la ocupación de suelos en el partido de General Pueyrredon. Si bien a nivel internacional y regional existen antecedentes donde se emplea la teledetección como insumo para analizar estas áreas (Baldini et al., 2016; Borràs et al., 2017; Mari, 2018; Suez et al., 2018; Lone y Mayer, 2019), en el partido de General Pueyrredon este tipo de estudios aún son escasos (Zulaica et al., 2012; 2013). De esta manera, se espera establecer una tipología de usos mediante clasificación digital que permita analizar espacios heterogéneos, como son los periurbanos, especialmente asociados con áreas de producción intensiva. 
Figura 1. Localización del área de estudio: partido de General Puevrredon y periurbano marplatense

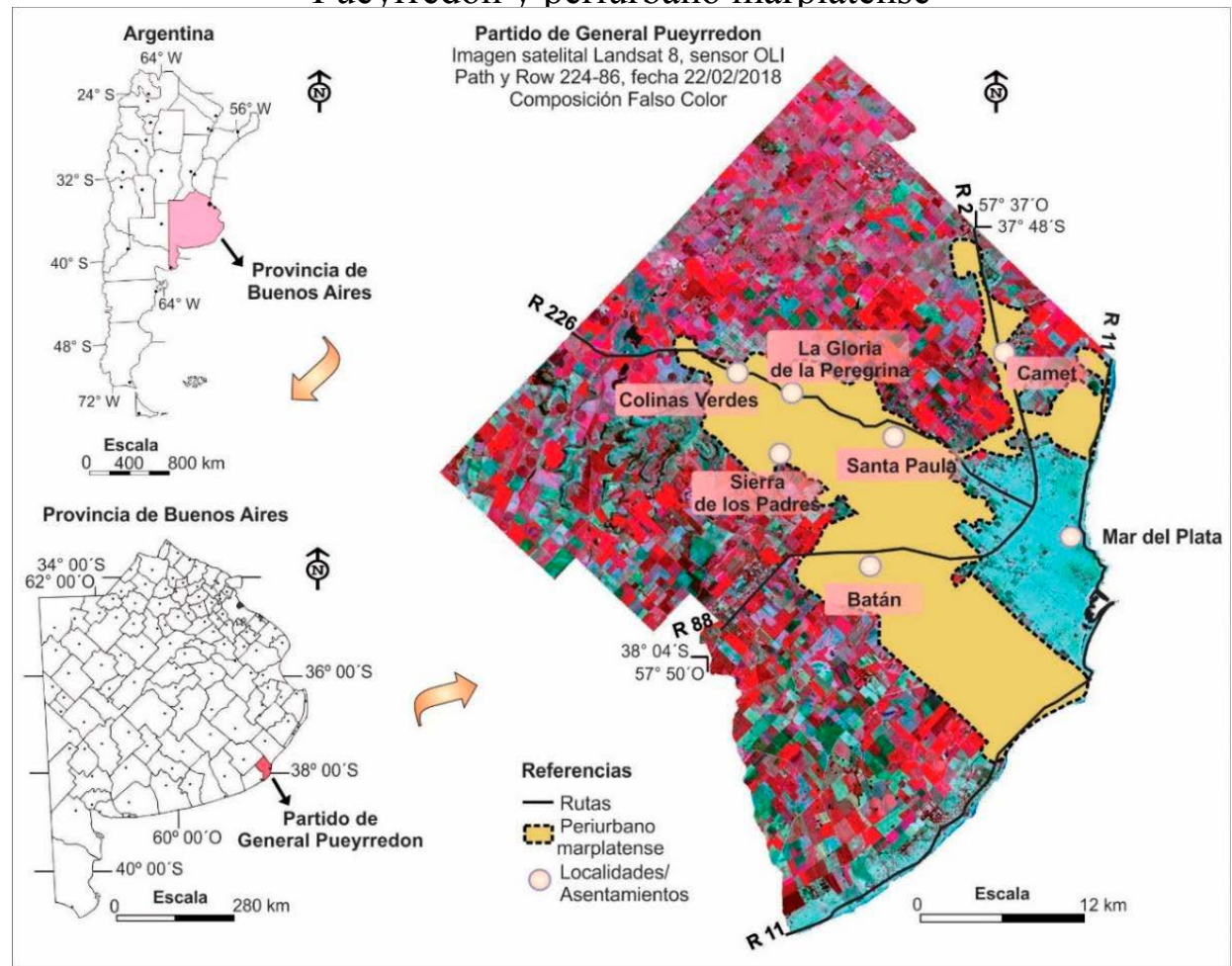

Fuente: Elaboración personal sobre la base de Zulaica et al. (2018).

\section{Materiales y métodos}

\section{Determinación de usos del suelo presentes en el partido de General} Pueyrredon

Para llevar a cabo la identificación de los usos de suelo, se prosiguió a la selección y descarga de una imagen satelital Landsat 8 sensor OLI (Path/ Row: 224/86). La misma fue obtenida del portal de imágenes satelitales EarthExplorer (https://earthexplorer.usgs.gov/) del Servicio Geológico de los Estados Unidos y su fecha de adquisición corresponde al $22 / 02 / 2018^{4}$. De modo general, el procesamiento se dividió en tres etapas: preprocesamiento, procesamiento propiamente dicho y posprocesamiento.

4 Se pretendió que la imagen haya sido tomada en época primavero-estival (del hemisferio sur), ya que en ese momento del año se visualiza la mayor producción intensiva, característica del cinturón hortícola marplatense. 
Para ello se empleó el software ENVI 4.5 (Reserch System Inc., Boulder, CO, USA).

\section{Preprocesamiento:}

Esta primera etapa incluyó la corrección radiométrica. Primeramente, se transformaron los ND (niveles o números digitales) almacenados para cada banda y píxel a valores de radiancia (Chander et al., 2009). En segundo lugar, estos valores se convirtieron en valores de reflectividad a tope de la atmósfera (TOA), sin considerar efectos atmosféricos y asumiendo una superficie uniforme Lambertiana bajo condiciones libre de nubes. Luego, se realizó una corrección atmosférica en la cual la reflectividad TOA se transformó a reflectividad de superficie asumiendo también una superficie uniforme Lambertiana bajo condiciones libre de nubes (Schroeder et al., 2006).

Por otra parte, la corrección geométrica no fue necesaria, ya que la imagen utilizada en este trabajo fue preprocesada por el Sistema de Generación de Productos Landsat y corresponde a un nivel de procesamiento L1TP. Esta nomenclatura hace referencia a que las imágenes se encuentran georreferenciadas (además de que están calibradas radiométricamente en ND). La imagen adquirida se encuentra en la proyección UTM, Zona 21 Sur, y datum WGS-84. Una vez realizada la corrección radiométrica y atmosférica, se recortó el área de estudio sobre la imagen procesada mediante la aplicación del vector correspondiente al partido de General Pueyrredon. Luego, se efectuó una composición falso color con las bandas del infrarrojo cercano, rojo y verde $(5,4,3$ respectivamente), ya que facilita principalmente la visualización de vegetación, aunque también permite distinguir cuerpos de agua, suelo desnudo, áreas urbanizadas, entre otras (Richards y Jia, 2006; Jones y Vaughan, 2010).

Procesamiento propiamente dicho:

En este trabajo, la segunda etapa consiste en la realización de una clasificación supervisada. La misma requiere tener conocimiento previo del terreno, ya que las categorías son definidas por el intérprete de acuerdo a sus objetivos y necesidades (Chuvieco, 1996). A fin de efectuar la clasificación, en primer lugar, se dividió el área de estudio en dos secciones, un área que incluye "áreas construidas" y otra que las excluye. Este procedimiento debió efectuarse para que el clasificador discrimine la "superficie construida" de los "invernáculos", ya que poseen una reflectancia similar. 
Se construyeron dos máscaras y se realizó la clasificación supervisada de manera individual.

A continuación, se orientaron las Regiones de Interés (ROIs) que definen las clases de uso de suelo distinguibles en el área de estudio y que luego empleará el clasificador (tanto para la clasificación como para los datos de referencia o "verdad de terreno"). Las clases que se identificaron fueron: "áreas construidas"; "áreas verdes-vacíos urbanos-residenciales abiertos"; "áreas hortícolas bajo cubierta"; "otras áreas productivas" y "cuerpos de agua superficiales". Las "áreas hortícolas a campo" no se incluyeron en la clasificación supervisada, por la dificultad que presentan este tipo de imágenes (resolución espacial media: $30 \mathrm{~m}$ en las bandas consideradas) para distinguir cultivos hortícolas de otras áreas agrícolas extensivas. Sin embargo, estas áreas se superpusieron como vectores al finalizar la clasificación.

En este sentido, se actualizó la digitalización ${ }^{5}$ de áreas hortícolas a campo y bajo cubierta presentadas en trabajos previos (Daga et al., 2017), a valores del año 2018. Respecto de las áreas bajo cubierta, fue necesario contar con datos precisos para determinar la exactitud de la clasificación considerando valores de superficie y de distribución espacial y, además, para identificar los invernáculos localizados en la imagen que incluye las "áreas construidas", que deberán superponerse como vectores al final del procedimiento.

Para orientar las ROIs y llevar a cabo la digitalización mencionada, se obtuvieron puntos GPS (Global Positioning System) mediante salidas de campo y del visor de imágenes de mayor resolución espacial del software Google Earth Pro; y se efectuaron entrevistas a informantes clave.

Previo a la clasificación, fue evaluada la separabilidad de las ROIs ${ }^{6}$. Seguidamente, se seleccionó y aplicó el clasificador Support Vector Machine (Máquinas de Soporte Vectorial) con el kernel radial basis function para ambas clasificaciones, situación fundamentada en los resultados satisfactorios obtenidos en comparación con otros clasificadores. En relación con ello, las Máquinas de Soporte Vectorial poseen la habilidad de manejar adecuadamente cantidades pequeñas de áreas de entrenamiento, con niveles de precisión más elevados que otros métodos tradicionales (Mantero et al., 2005).

5 Para ello se empleó el software ArcGIS 10.4.1. (Environmental Systems Research Institute, Inc. Redlands, California, USA).

6 En la imagen que incluye las "áreas construidas", la separabilidad fue de 1,88, y en la imagen que las excluye los valores obtenidos variaron entre 1,82 y 1,99 . 
Consecuentemente, si bien el algoritmo más empleado en clasificaciones supervisadas es el de Máxima Verosimilitud, en los últimos años se evidencia un gran interés en las Máquinas de Soporte Vectorial (Argañaraz y Entraigas, 2011; Mountrakis et al., 2011; Cavallaro et al., 2015).

\section{Posprocesamiento:}

Esta etapa incluyó, inicialmente, la construcción de la matriz de confusión para evaluar la efectividad de la clasificación a partir de los valores de Precisión Global o Total y el coeficiente Kappa (Congalton, 1991; Foody, 2002; Lillesand et al., 2004). Posteriormente, se obtuvieron los estadísticos para cada clase a partir de la función class statistics localizada en el menú de post classification. Para conocer el valor de superficie de las áreas hortícolas a campo, se creó y aplicó una máscara sobre ambas clasificaciones. El mismo procedimiento se realizó para identificar la superficie ocupada por las áreas hortícolas bajo cubierta que se encontraban en la imagen que incluye las "áreas construidas". Finalmente, las imágenes resultantes de la clasificación se unieron mediante la herramienta overlay, se superpusieron las áreas hortícolas a campo y las bajo cubierta (de la imagen que incluye las "áreas construidas"), se exportó en formato imagen y se confeccionó el mapa temático final.

\section{Identificación de usos del suelo en el periurbano marplatense}

En primera instancia, se llevó a cabo la digitalización del periurbano de Mar del Plata sobre la base de trabajos previos (Zulaica et al. 2012; 2018), mediante la utilización del software ArcGIS 10.4.1. Dicha capa de información se utilizó para recortar la clasificación supervisada original del Partido, a través de la creación de una máscara ${ }^{7}$.

Consecutivamente, se extrajeron los estadísticos para las clases de uso del suelo identificadas anteriormente. Con el fin de obtener el valor de superficie de las áreas hortícolas a campo y bajo cubierta (las que se encuentran en la imagen que incluye las "áreas construidas"), se creó y aplicó una máscara de estas áreas sobre ambas clasificaciones.

Luego, al igual que en la clasificación del Partido, las imágenes obtenidas se unieron mediante la herramienta overlay. Por último, se incorporaron como vectores las áreas hortícolas a campo y las áreas bajo cubierta (de la imagen que incluye las "áreas construidas"), se exportó el resultado en formato imagen y se confeccionó el mapa temático final.

7 Esta máscara se aplicó tanto a la imagen que incluye las "áreas construidas" como a la que las excluye. 


\section{Evolución de la actividad hortícola}

La caracterización de la evolución de la superficie hortícola demandó el análisis de la variación de la superficie dedicada a esta actividad y de las principales transformaciones socioproductivas. En primer lugar, se efectuó una comparación de los resultados obtenidos en la clasificación supervisada a nivel de Partido, con estadísticos de trabajos previos (Zulaica et al., 2013; Adlercreutz et al., 2018), datos de INTA (2017) y Censos hortícolas locales y provinciales (CHGP, 1994; CHB, 2001; CHFBA, 2005).

Finalmente, las transformaciones socioproductivas se abordaron a través de trabajos antecedentes realizados en el área de estudio (Bocero, 2002; Carrozzi y Viteri, 2002; Burmester, 2004; Bocero y Prado, 2007; Manzoni et al. 2015; González et al., 2017; Adlercreutz et al., 2018; Zulaica et al., 2019) y entrevistas a informantes clave que desarrollan sus tareas en el territorio: técnicos del Instituto Nacional de Tecnología Agropecuaria (INTA)-Mar del Plata; presidente de la Asociación Frutihortícola de Productores y afines del partido de General Pueyrredon; presidente de la Asociación de Pequeños Productores de Mar del Plata, Batán y El Boquerón; representante de la Unión de Trabajadores de la Tierra-Mar del Plata.

\section{Resultados y discusión}

\section{Los usos del suelo en el Partido y en el periurbano marplatense}

De acuerdo con lo expresado en el apartado de materiales y métodos, en primera instancia se exponen los resultados alcanzados respecto de la clasificación de los usos del suelo presentes en el Partido. A fin de determinar la exactitud del proceso de clasificación y observar posibles errores cometidos por el clasificador al asignar cada una de las clases, se elaboró una matriz de confusión. Esta es una manera efectiva de representar la exactitud de un mapa debido a que se describen los errores de inclusión (comisión) y errores de exclusión (omisión) de la clasificación para cada categoría o clase (Congalton, 1991).

En este sentido, la clasificación de la imagen que incluye las "áreas construidas" obtuvo una Precisión Global de 99,14\% y Coeficiente Kappa de 0,97, mientras que la imagen que las excluye alcanzó un valor de 99,82\% y Coeficiente Kappa de 0,90. Los resultados evidencian una alta 
precisión, considerando que los valores de $\mathrm{Kappa}^{8}$ varían entre +1 y -1 (Cohen, 1960) y que es esperado que éstos sean positivos debido a la correlación positiva que debiera existir entre la clasificación y los datos de referencia o "verdad de terreno" (Congalton y Green, 2002). Respecto de la Precisión Global, si bien no hay un rango establecido, se recomienda comúnmente que los valores superen el $85 \%$ (Foody, 2002).

Una vez determinada la exactitud de la clasificación, es posible observar que en el partido de General Pueyrredon conviven 6 usos del suelo principales (Figura 2). A continuación, en la Tabla 1, se observan los estadísticos obtenidos para cada uno de ellos.

Tabla 1. Usos del suelo presentes en el partido de General Pueyrredon al año 2018

\begin{tabular}{|c|c|}
\hline Clases de uso & Superficie ocupada $\mathbf{( k m}^{\mathbf{2}} \mathbf{~}$ \\
\hline Áreas construidas & 125,23 \\
Áreas verdes-vacíos urbanos-residenciales abiertos & 105,36 \\
Áreas hortícolas bajo cubierta & 6,58 \\
Áreas hortícolas a campo & 96,18 \\
Otras áreas productivas & 1122,97 \\
Cuerpos de agua superficiales & 4,42 \\
\hline Total & $\mathbf{1 4 6 0 , 7 4}$ \\
\hline
\end{tabular}

Fuente: Elaboración personal.

- Las "áreas construidas" ocupan el 8,57\% del total de los usos del Partido. No se circunscriben únicamente a zonas predominantemente urbanas, sino que también incluyen a aquellas localidades y asentamientos ubicados en el periurbano marplatense.

El Partido cuenta con un diagnóstico realizado en colaboración entre el BID y MGP (2013) donde, entre otras cuestiones, se analizó la evolución de la huella urbana a partir de imágenes satelitales. Los resultados demostraron que entre los años 1985 y 2001, la huella urbana creció casi un $10 \%$, de 114,22 a $124,33 \mathrm{~km}^{2}$. Entre 2001 y $2011\left(124,56 \mathrm{~km}^{2}\right)$, en contraste, el crecimiento fue prácticamente nulo de apenas un $0,15 \%$.

8 Landis y Koch (1977) determinaron posibles rangos del coeficiente Kappa: valores mayores a 0,80 representan una aceptación fuerte; valores entre 0,40 y 0,80 refieren a una aceptación moderada; y valores debajo de 0,40 evidencian una aceptación pobre. 
El cambio registrado en la huella urbana en el primer período podría explicarse principalmente por la ocupación de espacios abiertos y áreas de cultivos, registrándose en especial desarrollos de densidades medias y altas. Esta información coincide con los resultados obtenidos en el presente trabajo, donde se conservaría el crecimiento lento planteado en el informe.

De acuerdo con datos del INDEC (2010), el Partido poseía 618.989 habitantes en ese año. El actual modelo de distribución de la población muestra una marcada concentración en la ciudad de Mar del Plata, particularmente en el área central, que disminuye paulatinamente hacia los bordes ejidales, siendo muy baja en el resto del Partido. Allí se destacan distintas localidades, parajes y barrios ligados a actividades primarias y terciarias (Sagua y Sabuda, 2015).

- Considerando las "áreas verdes-vacíos urbanos-residenciales abiertos", estas comprenden el arbolado urbano, plazas, parques y terrenos baldíos que abarcan el 7,21\% del total del área estudiada. Según datos del BID y MGP (2013), la ciudad posee 61,45 ha de espacio verde permanente por cada 100.000 habitantes, conformando un valor considerado aceptable según estándares internacionales (Sorensen et al., 1998). Sin embargo, según Karis (2017), quien identificó y cartografió los espacios verdes públicos del área urbana y periurbana de la ciudad, existiría una carencia de espacios verdes públicos en la mayor parte del área de estudio, siendo particularmente escasas las plazas y parques de más de 3,5 ha.

Por otra parte, los principales parques y reservas naturales (mayores a 10 ha) presentes en el Partido son parque Camet, parque de los Deportes, reserva Natural del Puerto y parques de Punta Mogotes, reserva integral Laguna de Los Padres y espacios verdes presentes en el paseo Costanero Sur. En relación con ello, los espacios verdes proveen diferentes servicios ecosistémicos, entre los que se destaca el servicio urbano de regulación de temperatura. En las áreas periurbanas de Mar del Plata aquel también se verifica, pero favorecido además por la vegetación proveniente de áreas agrícolas extensivas e intensivas y barrios residenciales de baja densidad (Mujica et al., 2019). 
- Respecto de las "áreas hortícolas bajo cubierta”, representan apenas el $0,45 \%$ de la superficie total del Partido y comprenden el 6,40\% del total de la superficie hortícola. Es importante mencionar que los estadísticos obtenidos para esta clase se asemejan a las estimaciones del INTA (2017), que refieren a un valor de $6,50 \mathrm{~km} 2$. Además, el valor también resulta similar al conseguido con la digitalización realizada $(7,26 \mathrm{~km} 2)$. Por otro lado, las "áreas hortícolas a campo" alcanzan un $6,58 \%$ de la extensión del Partido y representan casi la totalidad de las áreas hortícolas $(93,60 \%)$. El resultado obtenido también concuerda con lo planteado en INTA (2017), donde se precisó un área de $95,50 \mathrm{~km} 2$. De acuerdo con el organismo, los principales cultivos realizados a campo son choclo, lechuga y zanahoria; y bajo cubierta, tomate, pimiento y lechuga o espinaca.

- El uso denominado "otras áreas productivas" ocupa la mayor superficie del Partido (76,89\%), y hace referencia a otras actividades relevantes del área: la agricultura extensiva, ganadería, avicultura, minería e industria.

En este sentido, el sector primario posee una participación menor en el PBG, distribuido entre agricultura, ganadería, pesca y minería. Si bien la pesca no fue considerada al momento de determinar los usos del suelo, se trata de la actividad principal dentro del sector (Roveretti et al., 2013). Respecto de la ganadería, se produce ganado bovino (cría e invernada), ovino y equino, también se incluye la cría de aves de corral, huevos, lana y cuero, la producción de leche, entre otros (Mikkelsen et al., 2015). En cuanto a la producción de granos, se destacan como principales cultivos extensivos el trigo, la soja y el girasol. En el marco de procesos de "agriculturización" evidenciados (Manuel-Navarrete et al., 2005), como en el resto de la región pampeana, desde los años '70 hasta la actualidad se observaron marcadas reducciones en la superficie dedicada al girasol, el maíz y el trigo con la aparición de cultivares de soja en los años '80 (Mikkelsen et al., 2015). Según un estudio realizado por Auer et al. (2019) en la Cuenca Mar Chiquita, para la campaña 2013/14 se contabilizaban en el partido de General Pueyrredon unos 903,06 km² de áreas agrícolas-ganaderas. Si se considera que la superficie del Partido registrada dentro de la Cuenca es del $77 \%$, y que en la clasificación supervisada se incluyeron otros usos del 
suelo (agrupados en "otras áreas productivas"), los resultados coinciden con los obtenidos en el presente estudio.

En lo que respecta al sector minero, en General Pueyrredon esta actividad se encuentra instalada y desarrollada desde el año 1930, y puede dividirse en dos grandes grupos: minería de rocas de aplicación y minería de suelos -canteras ladrilleras- (Zulaica et al., 2012). La explotación de rocas se desarrolla principalmente en las zonas de Estación Chapadmalal y Batán (sitios de canteras y plantas de trituración de ortocuarcitas), y le sigue en orden de importancia la localidad de Sierra de los Padres (Del Río et al., 2007). Por su parte, las canteras ladrilleras alcanzan una importante difusión en Batán, Estación Chapadmalal y El Coyunco (Zulaica et al., 2012).

Por otro lado, el desarrollo industrial es de mediana complejidad en la ciudad y se circunscribe en el periurbano a dos áreas específicas: el Parque Industrial (sobre eje Ruta Provincial $N^{\circ} 88$ ) y un Distrito Industrial (sobre Av. Presidente Perón- Ruta Provincial N 88), definido así por el Código de Ordenamiento Territorial, en el que predominan talleres y distribuidoras (Zulaica et al., 2012). Hacia el interior del sector secundario, la industria manufacturera aportaba en el año 1999 el 61,70\% del valor agregado al mismo, generado prioritariamente por tres ramas de la actividad: alimentación, textil y metalmecánica (Rearte y Ferraro, 2002).

- Por último, los “cuerpos de agua superficiales", integrados por arroyos temporales y permanentes, áreas anegadas y lagunas; son la clase de uso de menor extensión, ocupando solamente un $0,3 \%$ del total. Dentro de esta clase, se destaca la Laguna de Los Padres como principal exponente de importancia turística y área de reserva. Posee una superficie aproximada de 2,2 km2, que fluctúa de acuerdo a las precipitaciones regionales y su relación con el acuífero (Colasurdo et al., 2011). Por su parte, la escorrentía superficial es pequeña y no existen cursos de agua permanente importantes, a excepción del pequeño arroyo de la Tapera (Bocanegra y Custodio, 1994) y el arroyo de Los Padres (efluente y afluente de la laguna, respectivamente). El afluente discurre a través de campos hortícolas antes de desembocar en la laguna, y en oposición se localiza el efluente con una pequeña compuerta que regula el régimen hídrico de dicho cuerpo (Esquiús et $a l ., 2008)$. En función de lo enunciado anteriormente, los resultados 
obtenidos en la clasificación concuerdan, principalmente, con la superficie que abarca la laguna.

A continuación, se puntualiza en los usos del suelo presentes en el periurbano de Mar del Plata (Figura 2), cuyos límites han sido determinados en estudios previos (Ferraro et al., 2013; Zulaica y Ferraro, 2013). En este sentido, considerando la dinámica de estas áreas de interfase, la definición de sus límites no es una tarea sencilla. Para la ciudad de Mar del Plata, Zulaica y Ferraro (2013) han precisado el límite interior "urbano-periurbano" a partir del análisis de la extensión de servicios de saneamiento básico (agua de red y cloacas) y de la existencia de amanzanamiento. Por otra parte, el límite externo (borde periurbano-rural), es más difícil de determinar a partir de un criterio específico. De acuerdo con las autoras, este límite conforma una franja difusa cuya extensión varía de acuerdo al proceso de expansión urbana, que en este caso tiene lugar sobre los principales ejes de comunicación. En términos generales, este límite incorpora las actividades agrícolas intensivas y excluye las agrícolas y pecuarias extensivas; sin embargo, en el periurbano pueden observarse áreas destinadas a estas últimas actividades que, debido a la proximidad con otras incluidas en este espacio, se integran al mosaico.

Según esta definición teórica y a la vez operativa, el periurbano marplatense abarca $23,49 \%$ de la superficie total del Partido y los usos del suelo identificados exhiben la siguiente distribución (Tabla 2):

Tabla 2. Usos del suelo en el periurbano marplatense al año 2018

\begin{tabular}{|c|c|}
\hline Clases de uso & Superficie ocupada $\mathbf{( k m}^{\mathbf{}} \mathbf{)}$ \\
\hline Áreas construidas & 29,5 \\
Áreas verdes-vacíos urbanos-residenciales abiertos & 76,15 \\
Áreas hortícolas bajo cubierta & 4,38 \\
Áreas hortícolas a campo & 63,63 \\
Otras áreas productivas & 166,61 \\
Cuerpos de agua superficiales & 2,92 \\
\hline Total & $\mathbf{3 4 3 , 1 9}$ \\
\hline
\end{tabular}

Fuente: Elaboración personal. 
En función de lo observado, es posible afirmar que el uso que tiene mayor representatividad espacial es el de "otras áreas productivas", abarcando un $48,55 \%$ del total. A su vez, representa un $14,84 \%$ de la superficie total de este uso a nivel de Partido. Luego, le sigue la clase de uso denominada "áreas verdes-vacíos urbanos-residenciales abiertos", ocupando un $22,19 \%$ del periurbano. El 72,28\% del total de estas áreas identificadas en el Partido se disponen en el periurbano, reafirmando lo planteado por Mujica et al. (2019) acerca de la participación de áreas verdes en zonas de interfase urbano-rural como fuentes de servicios ecosistémicos. Seguidamente, las "áreas hortícolas a campo" comprenden un $18,54 \%$ del total de usos a nivel de periurbano y, como es de esperarse, aquí se concentra la mayor cantidad de tierras destinadas a este uso, conformando un $66,16 \%$ del total.

Continuando con el orden de la importancia dada por la superficie que ocupan, le siguen las "áreas construidas", abarcando un $8,59 \%$ del total y apenas un $23,56 \%$ del total de áreas construidas en General Pueyrredon, coincidiendo con la baja densidad de ocupación característica de los espacios periurbanos (Rocca et al., 2014). Sin embargo, es importante destacar que, en términos demográficos, entre los años 2001 y 2010 estas áreas evidenciaron un crecimiento mayor incluso al verificado en el conjunto del Partido y en los sectores específicamente urbanos y rurales ( $\mathrm{Zu}$ laica y Celemín, 2014). Posteriormente, sobrevienen las "áreas hortícolas bajo cubierta" ocupando el 1,28\% del periurbano y abarcando el 66,56\% de las áreas bajo cubierta a nivel de Partido, observándose la preponderancia de estos sistemas en zonas de transición, al igual que sucede con el modo de producción a campo.

Finalmente, el uso del suelo con menor representación es el definido como "cuerpos de agua superficiales", significando escasamente un $0,85 \%$ del total y configurando un $66,06 \%$ del total de cuerpos de agua relevados para el Partido en estudio. 
Figura 2. Distribución de usos del suelo presentes en el partido de General Pueyrredon y periurbano marplatense

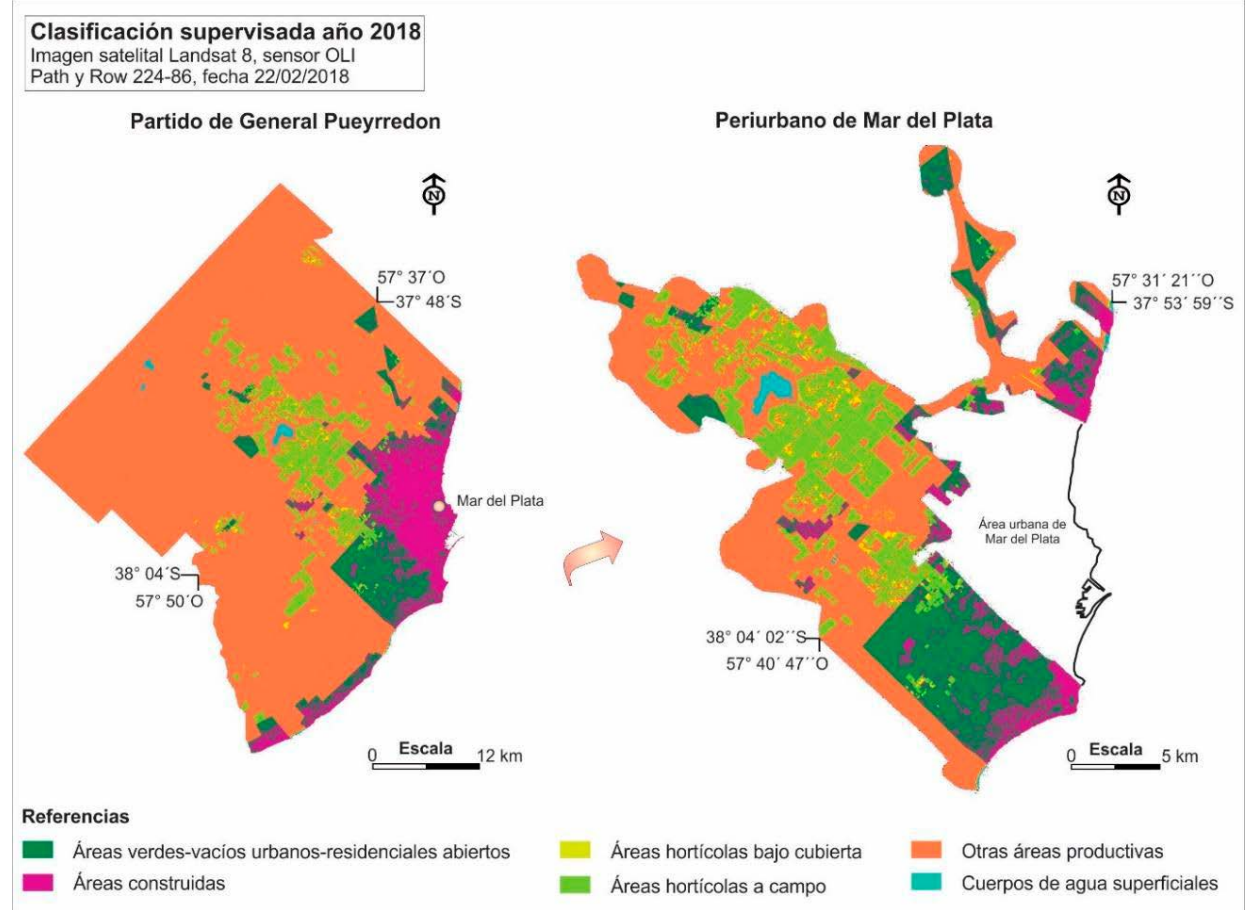

Fuente: Elaboración personal.

\section{Transformaciones de la actividad hortícola}

Si bien las áreas dedicadas a la horticultura abarcan una escasa extensión de las tierras del Partido (7,03\%), son destacables desde el punto de vista económico, aportando significativamente al PBG, como se especificó en apartados anteriores. En función de ello, y teniendo en cuenta la expansión e intensificación de la actividad, resulta relevante analizar estas transformaciones en términos de variación de superficies y características socioproductivas.

Considerando trabajos previos (Zulaica et al., 2013) y los resultados obtenidos en la clasificación supervisada, desde el año 1989 hasta la actualidad se evidencia una clara expansión de la actividad que asciende a un $115,88 \%$. Al momento de discriminar entre áreas a campo y bajo cubierta (Figura 3), es posible afirmar que las primeras mostraban un crecimiento constante hasta el año 2007, donde comenzaron a descender. Desde el año 
2010 hasta el presente las superficies se mantuvieron estables y sin mayores modificaciones, alcanzando valores entre $94 \mathrm{~km}^{2}$ y $96 \mathrm{~km}^{2}$. En relación con las áreas bajo cubierta, el avance fue paulatino, sin grandes saltos desde el mismo año.

Figura 3. Variación de la superficie hortícola en el partido de General Pueyrredon

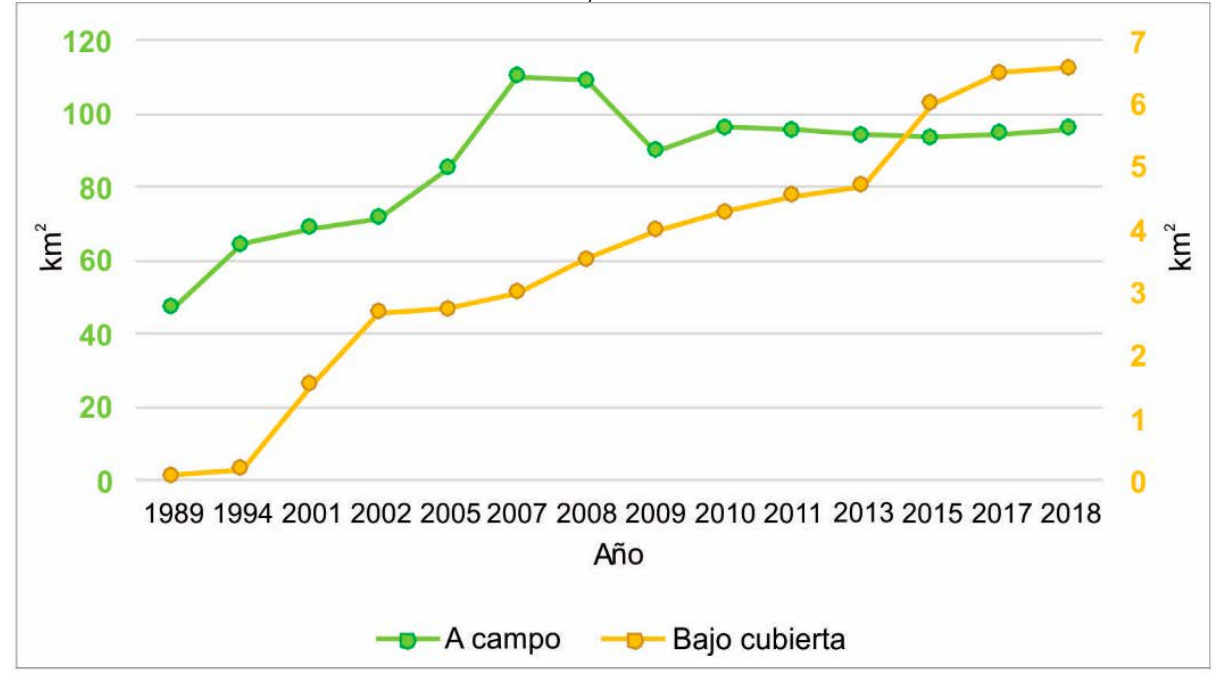

Fuente: Elaboración personal sobre la base de CHGP (1994), Zulaica et al. (2013), INTA (2017), Adlercreutz et al. (2018) y clasificación supervisada del presente trabajo.

De acuerdo con las entrevistas efectuadas, los momentos de crecimiento se observan cuando hay buenos márgenes económicos $\mathrm{y}$, principalmente, cuando hay rentabilidad de los cultivos bajo cubierta de tomate y pimiento, ya que en el Partido el reemplazo del tomate a campo fue prácticamente absoluto. Al respecto, es posible evidenciar que la implementación de invernáculos en las ciudades de Mar del Plata y en La Plata (principal cinturón hortícola de Argentina), no se dio de la misma manera. En esta última, las áreas bajo cubierta ocupan en la actualidad aproximadamente el $75 \%$ de la superficie hortícola total (Staviski, 2010), situación contraria a la visualizada en Mar del Plata.

La diferenciada implementación de invernáculos en ambos cinturones podría atribuirse a que en La Plata el reemplazo se dio fundamentalmente sobre los cultivos de hoja (principalmente lechuga), los cuales 
representan un gran porcentaje (36\%) de las tierras cultivadas, de acuerdo a datos del CHFBA (2005). Si esta situación hubiese ocurrido en el cinturón verde marplatense, la superficie bajo cubierta podría ser considerablemente más elevada, ya que en el mismo año el porcentaje de lechuga alcanzaba el $41 \%$ del total. En este sentido, en los últimos años se observa una aparente estabilización respecto de la implementación de invernáculos debido al incremento en el costo de los insumos, algunos de los cuales cotizan en dólares. Al comparar los datos calculados por INTA, con los obtenidos en los censos hortícolas bonaerenses de 2001 y 2005, resulta evidente que en estos últimos los resultados demuestran una subestimación. El mencionado escenario se manifiesta especialmente en las áreas a campo, arrojando valores entre 18,41\% y 62,96\% (año 2001 y 2005 respectivamente) por debajo a lo indicado por INTA.

Finalmente, en función de los estudios antecedentes revisados y de las entrevistas a informantes calificados efectuadas, a continuación, en la Tabla 3 se detallan las etapas y sucesos más relevantes que se sucedieron en la horticultura marplatense y que determinan la superficie ocupada por la actividad, sus variaciones y patrones de distribución. 
Daiana Yael Daga - Laura Zulaica - Patricia Vazquez

The peri-urban Mar del Plata (Argentina): digital classification of land uses and analysis of transformations

in the horticultural belt

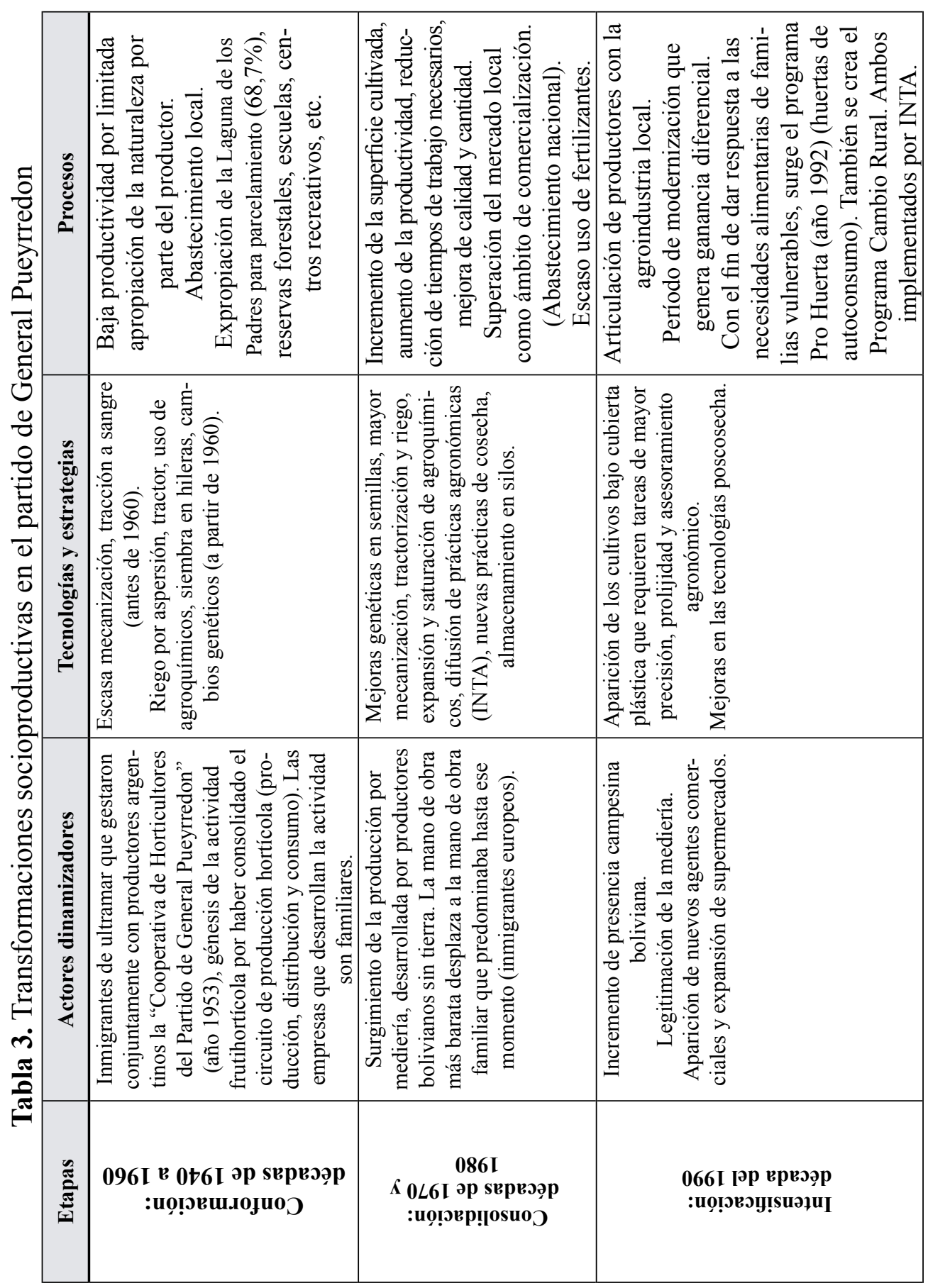

194 Revista Geográfica de América Central. No 65(2)

ISSN 1011-484X • e-ISSN 2215-2563 / Julio-diciembre 2020 
Daiana Yael Daga - Laura Zulaica - Patricia Vazquez

El periurbano de Mar del Plata (Argentina): clasificación digital de los usos del suelo y análisis de las transformaciones en el cinturón hortícola

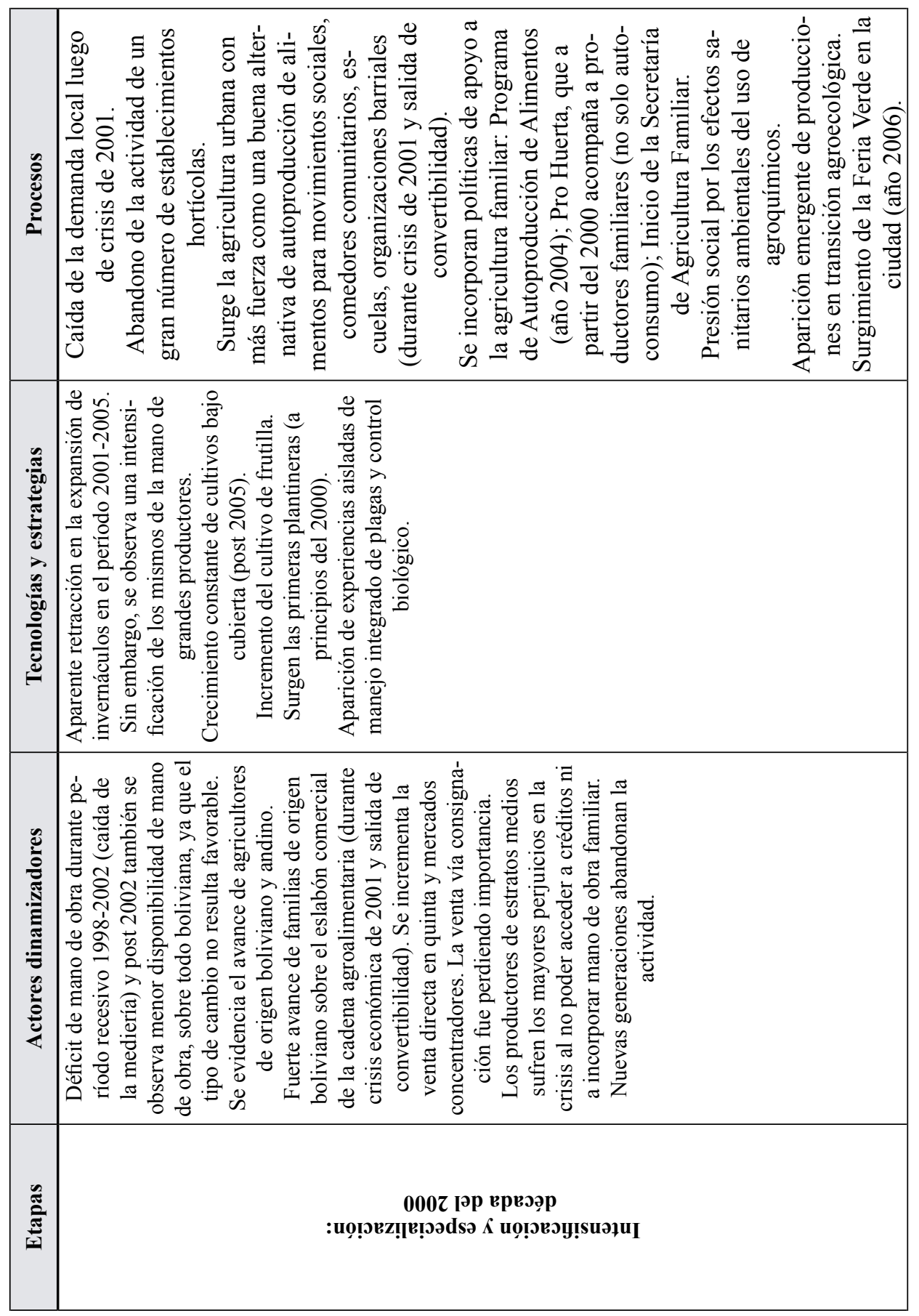


Daiana Yael Daga - Laura Zulaica - Patricia Vazquez

The peri-urban Mar del Plata (Argentina): digital classification of land uses and analysis of transformations

in the horticultural belt

\begin{tabular}{|c|c|c|}
\hline & 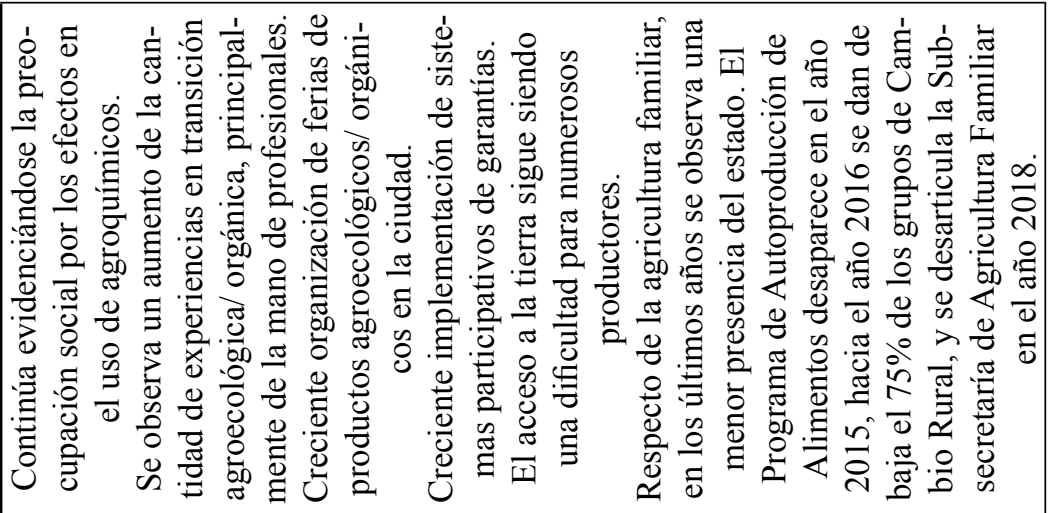 & \\
\hline & 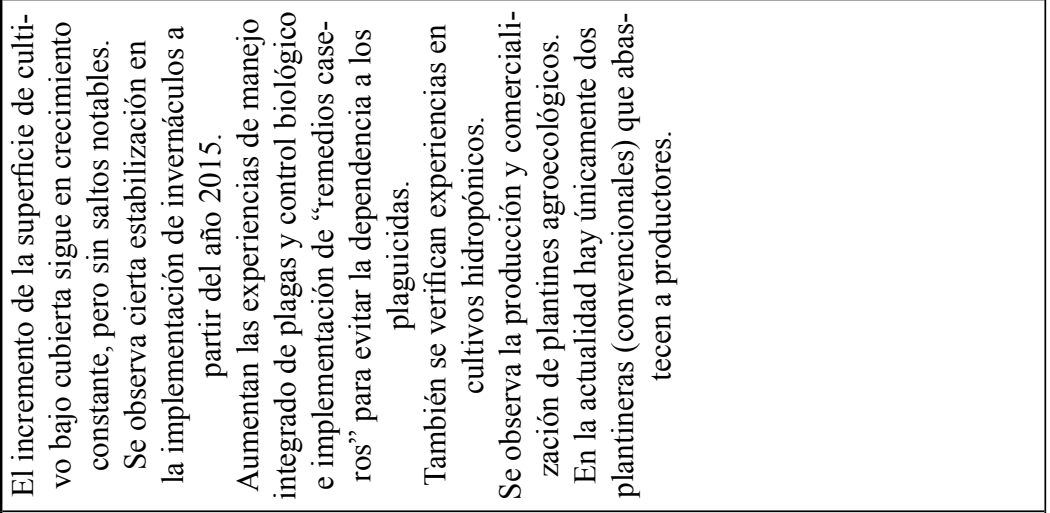 & \\
\hline & 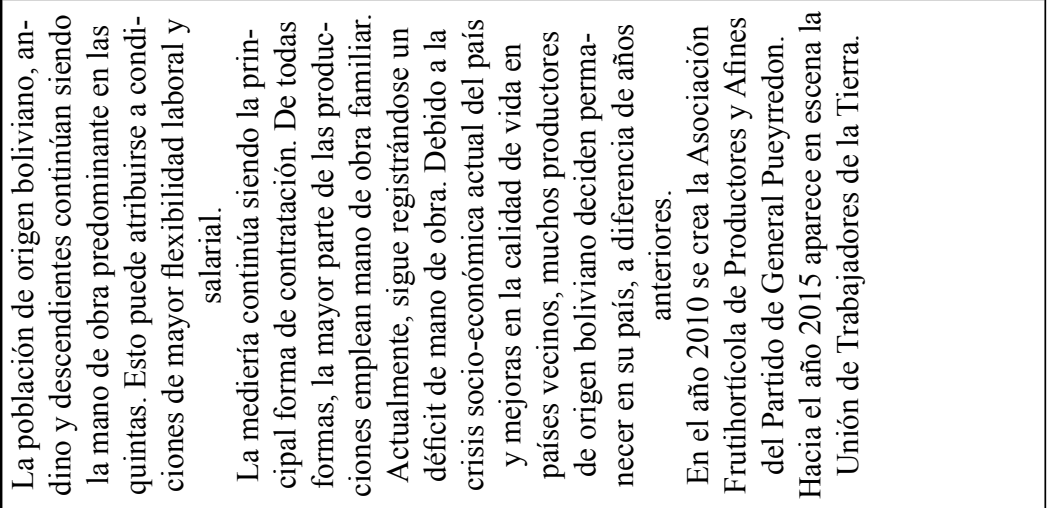 & \\
\hline 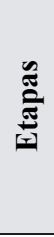 & $\begin{array}{l}\text { Estabilización de la actividad y expansión de nuevas formas de producción: } \\
\text { década del } 2010 \text { en adelante }\end{array}$ & \\
\hline
\end{tabular}

196 Revista Geográfica de América Central. No 65(2)

ISSN 1011-484X • e-ISSN 2215-2563 / Julio-diciembre 2020

Doi: http://dx.doi.org/10.15359/rgac.65-2.7 


\section{Conclusiones}

El partido de General Pueyrredon exhibe una gran diversidad de actividades, que caracterizan los usos del suelo del periurbano marplatense. De acuerdo con la clasificación realizada, es posible distinguir seis usos predominantes, siendo la denominada "otras áreas productivas" aquella que ocupa la mayor superficie $(76,89 \%)$ y "cuerpos de agua superficiales", la de menor representatividad. Si bien en el área convergen diversos usos, se destaca el hortícola generando beneficios económicos a la ciudad y posicionándola como segundo cinturón verde en importancia del país. Esta actividad se emplaza principalmente en el periurbano de la ciudad; áreas complejas donde es significativa la coexistencia de distintas actividades o usos del suelo. Allí las "áreas hortícolas" (a campo y bajo cubierta) representan el 19,82\% del total, siendo superadas, en términos de superficie ocupada, por "otras áreas productivas” y "áreas verdes-vacíos urbanosresidenciales abiertos".

En función de lo indicado, es relevante señalar que la horticultura ha atravesado diferentes etapas, iniciando como actividad de subsistencia de la mano de inmigrantes europeos, hasta lograr abastecer tanto al mercado local como también regional. Es notable la expansión e intensificación que ha tenido la actividad, incorporando diferentes tecnologías, entre ellas la del invernáculo, para disponer de frutas y hortalizas en toda época del año. A pesar de ello, esta tecnología no reemplaza el cultivo a campo, sino que lo complementa.

Por otra parte, es importante considerar que, así como sucede en otros cinturones hortícolas del país, la población comienza a atestiguar diferentes problemáticas ambientales derivadas del actual modelo de producción. Surgen tensiones acerca de la aplicación de plaguicidas en áreas residenciales lindantes a los campos, especialmente debido a las implicancias en la salud (enfermedades por exposición crónica) y contaminación del recurso hídrico; y se exigen nuevos modos de producir superadores, como es la agroecología, evidenciándose cada vez más experiencias a nivel local.

Para finalizar, los resultados alcanzados conforman una base que permitirá analizar la evolución de los usos del suelo en diferentes cortes temporales, planteándose la necesidad de profundizar en estudios de impacto ambiental de la actividad para avanzar hacia sistemas hortícolas más 
sustentables. Se espera que los resultados obtenidos en este trabajo y el procedimiento metodológico empleado contribuyan al diseño de estrategias de gestión conducentes a los Objetivos de Desarrollo Sostenible en la escala local, y transferibles a otras áreas periurbanas.

\section{Referencias}

Adlercreutz, E., Francucci, M. y Szczesny, A. (2018). Análisis sobre la evolución de la superficie hortícola a campo y bajo cubierta en general y por cultivo (2000-2017) - información clave para orientar la evolución del cinturón hortícola de Mar del Plata. Revista visión rural (nov-dic).

Alperín, M. I., Borges, V. G. y Sarandón, R. (2002). Caracterización Espacial de los Tipos de Cobertura de Suelo usando Técnicas Geoestadísticas a partir de Información Satelital. Revista de la Facultad de Agronomía, La Plata, 105(1), 40-51.

Argañaraz, J. P. y Entraigas, I. (2011). Análisis comparativo entre las máquinas de vectores soporte y el clasificador de máxima probabilidad para la discriminación de cubiertas del suelo. Revista de Teledetección, 36, 26-39.

Atucha, A. J., Errazti, E., Lacaze, M. V., Labrunée, M. E., López, M. T. y Volpato, G. (2012). La estructura productiva del Partido de General Pueyrredon. Faces, (38-39), 57-81.

Auer, A., Maceira, N. y Mikkelsen, C. (2019). El proceso de agriculturización en territorios con diferente matriz ecológico-productiva. El caso de la cuenca Mar Chiquita, provincia de Buenos Aires, Argentina. Revista de geografia Norte Grande, (72), 27-53.

Baldini, C., Marasas, M. E., Palacios, P. y Drozd, A. A. (2016). Territorio en movimiento: Análisis de cambio del uso/cobertura del suelo en el partido de La Plata entre 2005 y 2015. En: I IUFRO Landscape Ecology Latin-American, Chile.

Barsky, A. (2005). El periurbano productivo, un espacio en constante transformación. Introducción al estado del debate, con referencias al caso de Buenos Aires. Scripta Nova. Revista electrónica de geografia y ciencias sociales, 9(194).

Barsky, A. (2010). La agricultura de "cercanías" a la ciudad y los ciclos del territorio periurbano. Reflexiones sobre el caso de la Región 
Metropolitana de Buenos Aires. En A. Nemirovsky (Coord.), Agricultura periurbana en Argentina y globalización. Escenarios, recorridos y problemas (pp. 15-29). Buenos Aires: FLACSO.

Barsky, A., Astelarra, S. y Galván, L. (2010). Horticultura periurbana: Implementación de un programa de "buenas prácticas" en Pilar. Apuntes de Investigación del CECYP, (17), 177-187.

Beuchle, R., Grecchi, R. C., Shimabukuro, Y. E., Seliger, R., Eva, H. D., Sano, E. y Achard, F. (2015). Land cover changes in the Brazilian Cerrado and Caatinga biomes from 1990 to 2010 based on a systematic remote sensing sampling approach. Applied Geography, 58, 116-127.

BID (Banco Interamericano de Desarrollo) y MGP (Municipalidad de General Pueyrredon) (2013). Plan de acción Mar del Plata sostenible. Mar del Plata: Dirección General de Coordinación MGP. Recuperado de: https://www.mardelplata.gob.ar/documentos/gobierno/plan $\% 20$ de\%20accion\%20mdp-bid.pdf. (Consultado en septiembre de 2019).

Bocanegra, E. y Custodio, E. (1994). Utilización de acuíferos costeros para abastecimiento. Dos casos de estudio: Mar de plata (provincia de Buenos Aires, Argentina) y Barcelona (Cataluña, España). Ingeniería del agua, 1(4), 49-78.

Bocero, S. (2002). Cultivos protegidos y problemas ambientales: un estudio de la horticultura marplatense en la década del noventa (Tesis de Maestría en Ciencias Sociales). FLACSO-UNMDP, Mar del Plata.

Bocero, S. y Prado, P. (2007). Horticultura y territorio. Configuraciones territoriales en el cinturón hortícola marplatense a fines de la década del noventa. Estudios Socioterritoriales. Revista de Geografía, (7), 98-119.

Borràs, J., Delegido, J., Pezzola, A., Pereira, M., Morassi, G. y CampsValls, G. (2017). Clasificación de usos del suelo a partir de imágenes Sentinel-2. Revista de Teledetección, (48), 55-66.

Burmester, M. (2004). Un estudio de caso: la problemática ambiental en la Cuenca Frutihortícola de la ciudad de Mar del Plata, Partido de General Pueyrredon (Tesis Maestría en Gestión Ambiental del Desarrollo Urbano). FAUD, UNMDP, Mar del Plata.

Cavallaro, G., Riedel, M., Richerzhagen, M., Benediktsson, J. A. y Plaza, A. (2015). On understanding big data impacts in remotely sensed image classification using support vector machine methods. IEEE 
Daiana Yael Daga - Laura Zulaica - Patricia Vazquez The peri-urban Mar del Plata (Argentina): digital classification of land uses and analysis of transformations in the horticultural belt

journal of selected topics in applied earth observations and remote sensing, 8(10), 4634-4646.

Carrozzi, L. y Viteri, M. L. (2002). Transformaciones en tecnología hortícola. Mar del Plata, Argentina. Revista Facultad de Ciencias Agrarias, UNCuyo, 34(2), 81-85.

Chander, G., Markham, B. L. y Helder, D. L. (2009). Summary of current radiometric calibration coefficients for Landsat MSS, TM, ETM+, and EO-1 ALI sensors. Remote sensing of environment, 113, 893-903. CHB (2001). Censo Horticola Bonaerense. Buenos Aires: Ministerio de Agricultura, Ganadería y Alimentación de la Provincia de Buenos Aires, INDEC y Secretaría de Agricultura, Ganadería y Pesca de la Nación.

CHFBA (2005). Censo Hortiflorícola de Buenos Aires. Buenos Aires: Dirección Provincial de Economía Rural del Ministerio de Asuntos Agrarios, Dirección Provincial de Estadísticas del Ministerio de Economía, Secretaría de Agricultura, Ganadería, Pesca y Alimentos de la Nación, Consejo Federal de Inversiones.

CHGP (1994). Censo hortícola del partido de General Pueyrredon. Buenos Aires: Cooperativa de Horticultores del partido de General Pueyrredon y Secretaria de Agricultura Ganadería y Pesca (Buenos Aires).

Chuvieco, E. (1996). Fundamentos de Teledetección Espacial. Madrid: $\operatorname{RIALP}(568 \mathrm{p})$.

Cohen, J. (1960). A coefficient of agreement for nominal scales, Educational Psychological Measurement, 20(1),37-46.

Colasurdo, V., Díaz, O., Grosman, F. y Sanzano, P. (2011). Análisis de la calidad del agua de la laguna De los Padres: potencial uso para riego. Revista de la Facultad de Agronomía, La Plata, 110 (1), 20-25.

Congalton, R. G. (1991). A review of assessing the accuracy of classifications of remotely sensed data. Remote Sensing of Environment, 37, 35-46.

Congalton, R. G. y Green, K. (2002). Assessing the accuracy of remotely sensed data: principles and practices. Boca Ratón, Florida: CRC press (Taylor \& Francis group).

Daga, D., Zulaica, L., Ferraro, R. y Vazquez, P. (2017). Expansión e intensificación hortícola en el partido de General Pueyrredon, Argentina: sustentabilidad ecológica e impactos ambientales. Geografia Em Questão, 10, 102-117. 
Del Río, L., Caballé, M., Osterrieth, M., Kirilovsky, E., Bó, M. J., Denisienia, N., ... y Álvarez, J. (2007). Aplicación de índices de calidad ambiental para recuperación de canteras en zonas periurbanas (Provincia de Buenos Aires, Argentina). En: Congreso Internacional sobre Desarrollo, Medio Ambiente y Recursos Naturales: sostenibilidad a múltiples niveles y escalas, Universidad Mayor de San Simón, Cochabamba.

Di Pace, M. (2001). Sustentabilidad urbana y desarrollo local. San Miguel: Curso de Postgrado en Desarrollo Local en Áreas Metropolitanas, Instituto del Conurbano, Universidad Nacional de General Sarmiento.

Di Pace, M. y Bartrons, H. (2004). Ecología de la ciudad, Buenos Aires: Prometeo-UNGS.

Esquiús, K., Escalante, A. y Solari, L. (2008). Algas epífitas indicadoras de calidad del agua en arroyos vinculados a la Laguna de Los Padres. Biología acuática, (24), 95-102.

Ferraro, R., Zulaica, L. y Echechuri, H. (2013). Perspectivas de abordaje y caracterización del periurbano de Mar del Plata, Argentina. Revista Letras Verdes, (13), 19-40.

Foody, G. M. (2002). Status of land cover classification accuracy assessment. Remote Sensing of Environment, 80, 185-201.

González, V., Diuorno, R., Caetano, F. y Rattin, J. (2017). Mar del Plata horticultural region evolution. Strategies and achievements for the productive adaptation before legal changes. Revista de la Facultad de Agronomía, La Plata, 116 ( ${ }^{\circ}$ especial), 97-106.

INDEC (2002). Censo Nacional Agropecuario. Buenos Aires: Instituto Nacional de Estadísticas y Censos.

INDEC (2010). Censo Nacional de Población, Hogares y Viviendas. Buenos Aires: Instituto Nacional de Estadísticas y Censos.

INTA (2017). Descripción de la producción en el Cinturón Hortícola de Mar del Plata. Mar del Plata: Oficina de Información Técnica Mar del Plata.

Jaramillo, L. V. y Antunes, A. F. (2018). Detección de cambios en la cobertura vegetal mediante interpretación de imágenes Landsat por redes neuronales artificiales (RNA). Caso de estudio: Región Amazónica Ecuatoriana. Revista de Teledetección, (51), 33-46. 
Daiana Yael Daga - Laura Zulaica - Patricia Vazquez The peri-urban Mar del Plata (Argentina): digital classification of land uses and analysis of transformations in the horticultural belt

Jones, H. G. y Vaughan, R. A. (2010). Remote sensing of vegetation: principles, techniques, and applications. New York: Oxford University Press (353 p).

Karis, M. C. (2017). Caracterización de los espacios verdes públicos en la ciudad de Mar del Plata, Argentina. Trabajo presentado en ARQUISUR, San Juan.

Landis, J. y Koch, G. (1977). The measurement of observer agreement for categorical data. Biometrics, 33, 159-174.

Lara, B. y Gandini, M. (2014). Quantifying the land cover changes and fragmentation patterns in the Argentina Pampas, in the last 37 years (1974-2011). GeoFocus, (14), 163-180.

Lillesand, T., Kiefer, R. W. y Chipman, J. (2004). Remote sensing and image interpretation. New Jersey, USA: John Wiley \& Sons.

Lone, S. A. y Mayer, I. A. (2019). Geo-spatial analysis of land use/land cover change and its impact on the food security in District Anantnag of Kashmir Valley. GeoJournal, 84(3), 785-794.

Mantero, P., Moser, G. y Serpico, S.B. (2005). Partially supervised classification of remote sensing images through SVM-based probability density estimation. IEEE Transactions on Geoscience and Remote Sensing, 43(3), 559-570.

Manuel-Navarrete, D., Gallopín, G., Blanco, M., Díaz-Zorita, M., Ferraro, D., Herzer, H., ... y Celis, A. (2005). Análisis sistémico de la agriculturización en la pampa húmeda argentina y sus consecuencias en regiones extrapampeanas: sostenibilidad, brechas de conocimiento e integración de políticas. Santiago de Chile: CEPAL, Serie Medio Ambiente y desarrollo, División de Desarrollo Sostenible y Asentamientos Humanos.

Manzoni, M., Zulaica, L., Kemelmajer, Y., Bisso, V., Padovani, B., Lempereur, C., González, C. y Copello, S. (2015). Aportes metodológicos para la evaluación de la sustentabilidad en sistemas agrícolas hortícolas en el sureste de la pcia. de Buenos Aires. En: V Congreso Latinoamericano de Agroecología, SOCLA, Buenos Aires.

Mari, N. (2018). Mapeo y Caracterización del CV: Dinámica territorial y los procesos de transformación Urbano-Rural. En B. Giobellina (coomp.), La alimentación de las ciudades, Transformaciones 
territoriales y cambio climático en el Cinturón Verde de Córdoba (pp.121-144). Córdoba, Argentina: Ediciones INTA.

Ministerio de Educación de la Nación (2010). La horticultura en Argentina. Informe final. Recuperado de: http://catalogo.inet.edu.ar/files/ pdfs/info_sectorial/horticultura-informe-sectorial.pdf. (Acceso en septiembre de 2019).

Mikkelsen, C., Celemín, J. y Rivière, I. (2015). Aporte a la comprensión de lo rural en el partido de General Pueyrredon. En P. Lucero (Ed.), Atlas de Mar del Plata y el partido de General Pueyrredon II: problemáticas socio-territoriales contemporáneas (pp. 305-340). Mar del Plata: EUDEM.

Mountrakis, G., Im, J. y Ogole, C. (2011). Support vector machines in remote sensing: A review. ISPRS Journal of Photogrammetry and Remote Sensing, 66(3), 247-259.

Mujica, C. M., Karis, C. M. y Ferraro, R. (2019). Paisaje urbano, infraestructura ecológica y regulación de la temperatura. Estudios del hábitat, $17(1), \mathrm{e} 062$.

Piazza, G., Vibrans, A., Liesenberg, V. y Refosco, J.L. (2016). Objectoriented and pixel-based classification approaches to classify tropical successional stages using airborne high-spatial resolution images. GIScience \& Remote Sensing, 53(2), 206-226.

Rearte, G. y Ferraro, C. (Comp.) (2002). Mar del Plata productiva: diagnóstico y elementos para una propuesta de desarrollo local. Buenos Aires: CEPAL.

Richards, J. A. y Jia, X. (2006). Remote Sensing Digital Image Analysis. An introduction. Berlin, Alemania: Springer.

Rocca, M.J., Lancioni, A., Sgroi, A., Carol, I. y Ríos, L. (2014). Sustentabilidad territorial e instrumentos de regulación del periurbano. En: XI Simposio de la Asociación Internacional de Planificación Urbana y Ambiente, Facultad de Arquitectura y Urbanismo, UNLP, La Plata. Roveretti, M. J., Atucha, A. J. y Lacaze, M. V. (2013). Producto Bruto Hortícola del Partido de General Pueyrredon: reglas institucionales, relaciones insumo-producto y composición del valor agregado. En: VIII Jornadas Interdisciplinarias de Estudios Agrarios y Agroindustriales, Facultad de Ciencias Económicas, UBA. 
Sagua, M. C. y Sabuda, F. G. (2015). ¿Territorios jóvenes en una comuna envejecida a nivel poblacional? Las recientes dinámicas de crecimiento demográfico asociadas al hábitat en la ciudad de Mar del Plata y el Partido de General Pueyrredon. 1991-2001-2010. En P. Lucero (Ed.), Atlas de Mar del Plata y el partido de General Pueyrredon II: problemáticas socio-territoriales contemporáneas (pp. 23-50). Mar del Plata: EUDEM.

Schroeder, T. A., Cohen, W. B., Song, C., Canty, M. J. y Yang, Z. (2006). Radiometric correction of multi-temporal Landsat data for characterization of early successional forest patterns in western Oregon. Remote Sensing of Environment, 103, 16-26.

Sequeira, N., Vazquez, P. y Zulaica, L. (2016). Impactos sobre el ecosistema derivados de la agriculturización en el partido de Benito Juárez, Buenos Aires, período 2003-2011. AMBIENS. Revista Iberoamericana Universitaria en Ambiente, Sociedad y Sustentabilidad, 2, 30-51.

Sorensen, M., Barzetti, V., Keipi, K. y Williams, J. R. (1998). Manejo de las áreas verdes urbanas. Washington D.C.: Inter-American Development Bank.

Staviski, A. (2010). Situación de la plasticultura en Argentina. Informe frutihortícola. Abril. Recuperado de: http://www.infofrut.com.ar/index. php?option=com_content\&view=article\&id=1069:plasticultura-enla-argentina\&catid=92:sanidad. (Consultado en octubre de 2019).

Suez, L. S., Barchuk, A. H. y Locati, L. (2018). Mapa de cobertura y uso de la tierra en el área periurbana de la ciudad de Córdoba. Aportes para el ordenamiento territorial. En B. Giobellina (coomp.), La alimentación de las ciudades, Transformaciones territoriales y cambio climático en el Cinturón Verde de Córdoba (145-168). Córdoba, Argentina: Ediciones INTA.

Vazquez, P. y Rivas, R. (2009). Transferencia de Información Basada en Sensores Remotos para la Toma de Decisiones de Usuarios No Expertos. Revista Ciencia, 4(8),49-59.

Vazquez, P., Zulaica, L., Sequeira, N. y Daga, D. (2019). Expansión agrícola y potenciales implicancias sobre los servicios ecosistémicos en los paisajes del partido de Necochea, Buenos Aires, Argentina. Acta Geográfica, 13, 171-196. 
Volante, J. N. y Paruelo, J. M. (2015). Is forest or Ecological Transition taking place? Evidence for the Semiarid Chaco in Argentina. Journal of Arid Environments, 123, 21-30.

Zulaica, L., Ferraro, R. y Vazquez, P. (2012). Transformaciones territoriales en el periurbano de Mar del Plata. Revista Geograficando, 8(8), 169-187.

Zulaica, L. y Ferraro, R. (2013). Lineamientos para el ordenamiento del periurbano de la ciudad de Mar del Plata (Argentina), a partir de la definición de sistemas territoriales. Revista Geografia em Questão, 6(1), 202-230.

Zulaica, L., Ferraro, R. y Vazquez, P. (2013). Transformaciones territoriales del periurbano de la ciudad de Mar del Plata (Argentina), entre 1989-1999 y 1999-2009. En: $14^{\circ}$ Encuentro de Geógrafos de América Latina, Lima, Perú.

Zulaica, L. y Celemín, J.P (2014). Condiciones de habitabilidad y crecimiento poblacional en el periurbano de la ciudad de Mar del Plata, Argentina. Revista Espaco e Geografia, 17, 281-321.

Zulaica, L., Vazquez, P. y Daga, D. (2018). Estimación de la erosión actual y potencial de suelos destinados a actividades hortícolas en el periurbano de Mar del Plata. En: V Jornadas Nacionales de Investigación en Geografía Argentina, Facultad de Ciencias Humanas, Universidad Nacional del Centro de la Provincia de Buenos Aires, Tandil.

Zulaica, L., Manzoni, M., Kemelmajer, Y., Bisso, V., Padovani, B., Lempereur, C., González, C. y Copello, S. (2019). Evaluación de la sustentabilidad en sistemas hortícolas del sudeste bonaerense: aproximación metodológica en el periurbano de Mar del Plata. Horticultura Argentina, 38(95), 41-61. 
